\title{
Testemunho, evidência e risco : reflexões sobre o caso da fosfoetanolamina sintética
}

Testimony, evidence and risk: reflections on the synthetic phosphoethanolamine case

Rosana Castro e Rafael Antunes Almeida

\section{(2) OpenEdition}

Edição electrónica

URL: http://journals.openedition.org/aa/1637

DOI: $10.4000 /$ aa. 1637

ISSN: 2357-738X

\section{Editora}

Programa de Pós-Graduação em Antropologia Social (UnB)

Edição impressa

Data de publição: 1 julho 2017

Paginação: 37-60

ISSN: 0102-4302

\section{Refêrencia eletrónica}

Rosana Castro e Rafael Antunes Almeida, «Testemunho, evidência e risco : reflexões sobre o caso da fosfoetanolamina sintética», Anuário Antropológico [Online], v.42 n.1 | 2017, posto online no dia 08 junho 2018, consultado o 27 abril 2021. URL: http://journals.openedition.org/aa/1637 ; DOI: https:// doi.org/10.4000/aa.1637

\section{(c) $(1)(9)$}

Anuário Antropológico is licensed under a Creative Commons Atribuição-Uso Não-Comercial-Proibição de realização de Obras Derivadas 4.0 International. 


\title{
Testemunho, evidência e risco: reflexóes sobre o caso da fosfoetanolamina sintética ${ }^{1}$
}

\author{
Rosana Castro \\ $\mathrm{UnB}$ \\ Rafael Antunes Almeida \\ UNILAB
}

No segundo semestre de 2015, as páginas dos maiores jornais do país foram tomadas por notícias a respeito de uma substância química que, apesar de existente havia décadas, era desconhecida do grande público. A fosfoetanolamina sintética (doravante FS), em sua forma armazenada em pequenas cápsulas, conseguiu entrecortar o monotema das denúncias e delaçóes de casos de corrupção nos altos escalóes do governo e ocupou posição de destaque no horário nobre da televisão aberta e nas páginas de periódicos jornalísticos e científicos nacionais e internacionais (Ledford, 2015).

A FS nos era também desconhecida e a descobrimos a partir do volume imenso de notícias on-line e na televisão a respeito de sua existência, que, embora longa, era eivada de ambiguidades a respeito de seus efeitos, caracterizados simultaneamente como promissores e suspeitos. De pronto, chamaram a nossa atenção os posicionamentos e argumentos contrapostos nas matérias publicadas no período, que cobriam a produção discursiva sobre a substância apontando-a como "a cura do câncer" ou como obra de "charlatanismo". A controvérsia ${ }^{2}$ estava em curso e, diante dela, diversas perguntas nos ocorreram: como uma mesma substância pode ser foco de caracterizaçôes tão distintas? Quais são os atores envolvidos nessa discussão e por que se posicionam táo oposta e vividamente? Que efeitos essa controvérsia parece ter provocado sobre os próprios atores que a constituem?

Tendo por base uma série de eventos transcorridos ao longo do debate público relativo às possibilidades e aos limites do uso terapêutico da FS durante o segundo semestre de 2015, buscamos responder neste artigo a essas questóes, mesmo que parcialmente. Tomamos como ponto de apoio o modo como os temas dos riscos, da evidência científica e do aparecer público de testemunhos se entrelaçaram nessa trama com aspectos controversos.

O trabalho se fez a partir da análise de material jornalístico publicado em veículos on-line de ampla divulgação, da presença da coautora do artigo em uma audiência pública no Senado Federal e do subsequente estudo das notas taquigráficas das falas de pacientes, médicos e agentes governamentais nesse evento. Também nos 
beneficiamos da participação em comunidades na internet dedicadas a partilhar informaçôes sobre a droga, que nos deram pistas sobre as estratégias dos coletivos para promover sua liberação junto às autoridades sanitárias.

Neste artigo, em um primeiro momento, faremos uma caracterização da própria droga e da controvérsia em torno dela a partir de notícias relativas à FS sob as perspectivas de diversos atores envolvidos em processos para a viabilização do acesso às cápsulas, bem como de documentos lançados por esses atores durante o período. Nesse caminho, ressaltaremos dois fatores que lançaram a FS sob tantos holofotes: o fato de ela ter sido alvo de um intenso litígio judicial envolvendo cientistas, pacientes, instituiçôes estatais e diferentes instâncias do próprio Judiciário; e a formação de coletivos de pacientes que, diante de investidas contrárias ao uso terapêutico da FS, se organizaram e vocalizaram publicamente uma demanda pelo registro sanitário da substância.

Em seguida, apresentaremos de modo mais sistemático os argumentos centrais acerca do uso terapêutico da FS com base na audiência pública realizada no Senado Federal, de modo a aprofundar alguns aspectos referentes ao engajamento dos atores na polêmica a partir dos temas da evidência científica, dos riscos e dos testemunhos. Nas últimas seçôes, localizamos na discussão que acompanhamos elementos analíticos compartilhados com outros contextos etnográficos nos quais também vigora o embate entre as narrativas de recuperação dos pacientes e os órgãos reguladores ou comunidades científicas. Assim, com base em conceitos como os de ética de consensibilidade, eticalidade subalterna (Bharadwaj, 2013) e biomoralidade (Rose, 2008a), analisamos os pontos centrais de tensão da controvérsia e apontamos para a capacidade que o testemunho tem de desafiar os procedimentos usuais de regulação.

\section{O início da controvérsia: midiatizaçáo, judicializaçáo e biossocialidade}

A notícia mais antiga que conseguimos localizar em veículos de grande alcance e circulação a respeito da FS foi publicada no portal G1 em 17 de agosto de 2015, trazendo a seguinte manchete: "Pacientes pedem na Justiça que USP forneça cápsulas de combate ao câncer”. O conteúdo da extensa matéria tinha como marco inicial o pleito judicial de pessoas com câncer pelo acesso às cápsulas:

pacientes com câncer brigam na Justiça para que a Universidade de São Paulo (USP) forneça cápsulas de fosfoetanolamina sintética. Segundo usuários, familiares e advogados, a substância experimental produzida no campus de São Carlos (SP) acumula resultados satisfatórios no combate à doença, inclusive com relatos de cura, mas não possui registro junto à Agência Nacional de Vigilância Sanitária (Anvisa) e, por isso, só está sendo entregue por decisão judicial (Piovezan, 2015). 
A judicalização é, assim, o tema a partir do qual a FS entra no cenário midiático nacional. Na matéria, a FS é caracterizada como substância experimental e produzida em âmbito universitário sem aval da Agência Nacional de Vigilância Sanitária (Anvisa). Nessas condiçóes, sua distribuição passou a estar condicionada a um processo de judicialização, sendo o acesso às cápsulas efetivado mediante demanda judicial de cada paciente interessado em utilizá-la. As razóes para a FS não ter registro sanitário aparecem adiante na matéria, a partir da apresentação histórica de seu desenvolvimento na USP.

De acordo com a matéria, a FS começou a ser pesquisada no início dos anos 1990, sob a coordenação do químico Dr. Gilberto Orivaldo Chierice, professor e pesquisador do Instituto de Química de São Carlos (IQSC), vinculado à USP. Ainda segundo esta fonte, nessa mesma década, o pesquisador Salvador Claro Neto, vinculado à pesquisa de Dr. Chierice, realizou a síntese laboratorial da FS. Realizadas pesquisas laboratoriais que encontraram evidências de que a FS tinha propriedades antitumorais, o IQSC estabeleceu uma parceria com o Hospital Amaral Carvalho, na cidade de Jaú (SP), que se responsabilizou pela condução de ensaios com a FS em pacientes com câncer. No entanto, o convênio com a instituição foi descontinuado e, portanto, "pessoas atendidas no hospital começaram a recorrer à universidade para obter a substância que antes recebiam na unidade de saúde. Também contaram sobre os efeitos para outras pessoas e a procura aumentou com o passar do tempo" (Piovezan, 2015).

Tendo o grupo de pesquisa da FS se responsabilizado pela entrega do composto àqueles que compareciam à universidade a partir de então, essa forma de distribuição e acesso às cápsulas prosseguiu por mais de vinte anos. A matéria não relata se os pesquisadores registraram a quantidade de pessoas que receberam as cápsulas durante esse tempo. Relata, entretanto, que "uma portaria mudou o sistema” de doaçôes de FS para pacientes com câncer (Piovezan, 2015).

A portaria, emitida em junho de 2014 pela diretoria do IQSC, segundo declaração postada em sua página na internet, estabelece que substâncias farmacêuticas e afins "só poderão ser produzidas e distribuídas pelos pesquisadores do IQSC mediante a prévia apresentaçáo das devidas licenças e registros expedidos pelos órgãos competentes determinados na legislação (Ministério da Saúde e Anvisa)" (USP, 2014). O documento acrescenta que a distribuição de substâncias farmacêuticas ficaria, a partir de entáo, condicionada à apresentaçáo de tais autorizações sanitárias e à aprovação suplementar da Diretoria do Instituto. Esta determinaçáo foi o moto para que os usuários da fosfoetanolamina precisassem recorrer à Justiça de São Paulo para ter acesso às cápsulas. 
Pouco mais de um ano depois da emissão da portaria, em 29 de setembro de 2015, uma manchete do portal do Estadão anunciava uma reviravolta no caso: "TJ suspende distribuição de suposto remédio contra o câncer" (Tomazela, 2015). O conteúdo noticiava que a decisão emitida pelo presidente do Tribunal de Justiça de São Paulo (TJ-SP), José Roberto Nalini, havia suspendido 368 liminares que obrigavam a USP a distribuir a FS para os requerentes. Segundo a matéria, a decisão estava baseada na percepção de "não haver comprovação de que a substância produza algum efeito no combate à doença” (Tomazela, 2015). Destaca-se, aqui, não só a suspeita sobre a FS que conduziu à medida do TJ, bem como a denotada pelo próprio veículo de mídia, que caracterizou a substância como "suposto remédio" (Tomazela, 2015).

O caso, contudo, apresentaria ainda desdobramentos distintos no interior do Poder Judiciário. Menos de dez dias após a publicação da decisão do TJ-SP, o Supremo Tribunal Federal se pronunciou, por meio de medida cautelar deferida pelo ministro Edson Fachin, que teve efeito de suspensão da decisão do TJ-SP. A decisão se refere ao requerimento de Alcilena Cincinatus, descrita no documento como paciente "em estado terminal de moléstia grave e, ante a ineficácia de todos os procedimentos médicos recomendados, foi-lhe indicada, por meio de laudo médico, a utilização da Fosfoetanolamina Sintética, a fim de mitigar os sintomas por ela apresentados" (Brasil, 2015). No documento que autoriza a entrega de cápsulas de FS à paciente, o ministro expressa que a falta de registro na Anvisa não implica necessariamente lesão à ordem pública e salienta que "há evidente comprovação de que a espera de um provimento poderá tornar-se ineficaz" (Tomazela, 2015).

A busca pela substância aparentemente aumentou após a decisão do ministro Edson Fachin e sua publicização na mídia. Segundo reportagem publicada em 28 de outubro de 2015 na Folha de S. Paulo, o efeito da medida do STF foi fazer com que os "processos sobre 'cápsula do câncer' congestiona[ssem] a Justiça em São Carlos” (Toledo, 2015).

Olhando para esse cenário, notamos que o caso da FS apresenta contrastes profundos tanto com o funcionamento normatizado de produção e acesso a substâncias farmacêuticas no Brasil quanto com o cenário da judicialização de medicamentos no país. Com relação ao primeiro aspecto, cabe salientar que a extensa regulamentação sanitária vigente vincula o uso de substâncias experimentais ao estrito contexto de pesquisas científicas e condiciona sua posterior produção e distribuição à autorização da Anvisa (Brasil, 1976; 2015a). A agência, em seu exercício regulatório, estabelece que quaisquer fabricantes de substâncias farmacêuticas devem apresentar resultados de estudos sistemáticos em humanos e 
não humanos para atestar a segurança e a eficácia de seus produtos (Castro, 2014). Nesse sentido, a fabricação e a distribuição para pacientes pelo cientista do IQSC ocorreram por mais de duas décadas em desacordo com as regulamentaçóes legais sem, aparentemente, ter sido interpeladas pelas autoridades sanitárias.

Por outro, são interessantes as conexóes parciais do caso da FS com o contexto da judicializaçáo de medicamentos no país. Por um lado, o recurso ao Judiciário com vistas ao acesso a tratamentos com base no direito universal à saúde é atualmente um fenômeno rotineiro e de amplas proporçóes (Chieffi \& Barata, 2009; Marques, 2008), do qual o caso da FS toma parte. Por outro, os casos de interpelação do Judiciário por acesso a medicamentos sem registro na Anvisa que conhecemos (Biehl \& Petryna, 2016; Machado et al., 2011; Vieira \& Zucchi, 2007) se afastam do caso da FS por não corresponderem a um contexto em que os produtos farmacêuticos estão desvinculados de pesquisas clínicas ou de fabricação por laboratórios farmacêuticos multinacionais.

Apesar da notoriedade do caso na mídia, outros fatos estiveram ligados ao salto na quantidade de petiçôes judiciais pela FS. De modo significativo, pacientes e seus familiares fizeram uso das redes sociais não só para trocar informaçôes sobre as modalidades de acesso às cápsulas por via judicial, mas também para organizar coletivamente uma demanda pela "liberação", pela Anvisa, da produção, prescrição e dispensaçáo da FS para uso terapêutico. ${ }^{3}$ A comunidade Fosfoetanolamina no Facebook, que conta com número expressivo de seguidores, desenvolveu uma campanha cujo slogan é "Quem tem câncer, tem pressa" e a promove nas redes sociais por meio das hashtags \#liberaanvisa, \#fosfoetanolamina e \#câncertemtratamento. ${ }^{4}$ Ademais, manifestaçóes coletivas presenciais em diversas unidades da Federaçáo levavam adiante a demanda pela autorização sanitária para produção, distribuição e uso da FS. A coautora deste artigo compareceu a diversas delas em Brasília (DF) e conheceu pacientes de lugares como São Paulo, Rio de Janeiro, Bahia, Minas Gerais e Goiás que organizavam manifestaçôes em seus estados.

Tanto virtual quanto pessoalmente, as articulaçôes coletivas em torno da FS se aproximaram da noção de biossocialidade de Rabinow (1999), visto que promoveram a reuniáo de pessoas por meio de um identificador biopatológico com a finalidade de compartilhar experiências e buscar atendimento de suas demandas pela medicação experimental perante o Estado. Além disso, gerou-se uma intensa controvérsia, cujos desdobramentos, nos meses seguintes, transcenderam as tensóes com os poderes Executivo e Judiciário, estendendo-se ao Congresso Nacional. Em razão das limitaçóes próprias ao espaço do artigo, nos limitamos a apresentar uma cronologia dos principais acontecimentos em torno da FS, de modo a melhor situar nosso foco analítico (Quadro 1). 


\section{Quadro 1 - Cronologia de eventos relativos à controvérsia envolvendo a fosfoetalonamina sintética}

\begin{tabular}{|l|l|}
\hline 1994 - 2014 & $\begin{array}{l}\text { FS é distribuída sem impedimentos normativos } \\
\text { do IQSC. }\end{array}$ \\
\hline Junho de 2014 & $\begin{array}{l}\text { Emite-se a Portaria do IQSC 1.389/2014, que } \\
\text { suspende a distribuição das cápsulas pela } \\
\text { universidade. }\end{array}$ \\
\hline A partir de junho de 2014 & $\begin{array}{l}\text { Os pacientes passam a acionar a Justiça para } \\
\text { conseguir liminares favoráveis à obtenção das } \\
\text { cápsulas. }\end{array}$ \\
\hline Setembro de 2015 & $\begin{array}{l}\text { O Tribunal de Justiça de São Paulo (TJ-SP) } \\
\text { suspende as liminares que garantiam a } \\
\text { obtenção das cápsulas pelos pacientes. }\end{array}$ \\
\hline Outubro de 2015 & $\begin{array}{l}\text { O Supremo Tribunal Federal (STF) suspende a } \\
\text { decisão do TJ-SP. }\end{array}$ \\
\hline Outubro, novembro e dezembro de 2015 & $\begin{array}{l}\text { O caso da FS ganha ampla publicidade e } \\
\text { catalisa a busca de pacientes pela droga. }\end{array}$ \\
\hline 29 de outubro de 2015 & Acontece audiência pública no Senado Federal. \\
\hline 8 de março de 2016 & $\begin{array}{l}\text { A Câmara dos Deputados aprova a Lei } \\
\text { 4.639/2016, que autoriza o uso da FS sem } \\
\text { registro sanitário. }\end{array}$ \\
\hline 22 de março de 2016 & $\begin{array}{l}\text { O Senado Federal aprova a Lei 13.269/2016, } \\
\text { que autoriza o uso da FS sem registro sanitário. }\end{array}$ \\
\hline 13 de abril de 2016 & $\begin{array}{l}\text { A Lei 13.269 é sancionada pela presidenta da } \\
\text { República. }\end{array}$ \\
\hline 19 de maio de 2016 & $\begin{array}{l}\text { O STF defere a Ação Direta de } \\
\text { Inconstitucionalidade 5.501 e suspende a } \\
\text { eficácia da Lei 13.269. }\end{array}$ \\
\hline & and \\
\hline
\end{tabular}

Optamos por descrever aqui apenas o primeiro evento de discussão pública institucionalizada a respeito da FS no Congresso, no qual os atores sociais que formavam o debate se encontraram, expuseram suas argumentaçóes e tiveram aportes de deputados e senadores para suas demandas. Ao fazê-lo, seguiremos a senda aberta por trabalhos como o artigo de Nelkin e Hilgartner, que, ao anunciarem a intenção de realizar um estudo sobre controvérsias em audiências públicas, observam:

com efeito, uma audiência é uma performance pública, um drama, um combate verbal ritualizado envolvendo múltiplos atores, todos em busca de reificar suas versóes da realidade, de controlar a definição e a interpretação da evidência e de convencer a corte da validade de suas posiçóes (1986:119). 
Partindo do debate público a respeito do possível banimento da presença de crianças com aids em escolas públicas de Nova York nos anos 1980, as autoras se valem do estudo da audiência pública para colocar um conjunto de perguntas com relação às "diferentes imagens do próprio risco" (Nelkin \& Hilgartner, 1986:120). De certo modo, essas perguntas são similares àquelas que gostaríamos de perseguir para o caso da FS: "como o risco da AIDS é definido? O quê, nas ideias dos protagonistas da audiência, são os cenários de risco?” (Nelkin \& Hilgartner, 1986:120). No caso aqui em tela, perguntamo-nos, de modo correlato, pelos modos como os agenciamentos do risco de uso da FS sustentam posicionamentos diversos diante do regime de procedimentos científicos e regulatórios previstos para o desenvolvimento de um medicamento no Brasil.

\section{A audiência pública no Senado: defesa da fosfoetanolamina $v s$. defesa dos procedimentos-padráo}

No dia 29 de outubro de 2015, o Senado Federal foi palco de uma audiência pública conjunta das Comissôes de Ciência, Tecnologia, Inovação, Comunicação e Informática (CCT) e de Assuntos Sociais (CAS) dedicada a informar os legisladores acerca de matéria do caso que vinha ganhando atençóes e mobilizaçóes crescentes. A audiência foi presidida pelo senador Cristovam Buarque (PDT-DF), ${ }^{5}$ que compôs a mesa de trabalhos com a senadora Ana Amélia (PP-RS) e o senador Ivo Cassol (PP-RO), e contou com a presença de senadores e deputados federais e estaduais, além de membros do Judiciário.

De modo semelhante ao que ocorrera no STF em 2008, por ocasião de audiência presidida pelo entáo ministro Carlos Ayres Britto acerca do uso de embrióes na pesquisa com células-tronco (Almeida, 2010), e ao que ocorrera na Câmara dos Deputados sobre o mesmo tema (Cesarino, 2006), o Congresso foi tomado por jornalistas, pacientes de câncer acompanhados por seus familiares, representantes de associaçôes médicas e farmacológicas e cientistas interessados no futuro da FS. Todas as cadeiras da galeria reservada ao público estavam ocupadas, bem como um pequeno alambrado que fica do lado oposto à porta de entrada.

Nas apresentaçóes que compunham a audiência pública, dois grupos se destacavam: de um lado estavam os cientistas, médicos e pacientes envolvidos com a FS e, de outro, representantes de agências do Estado. Os primeiros defendiam a qualidade, segurança e eficácia da substância. Os representantes das agências do Estado, notadamente a Anvisa e os Ministérios da Saúde e de Ciência, Tecnologia e Inovação, por sua vez, afirmavam que os procedimentos previstos por tais órgãos para a produção de medicamentos não haviam sido observados no caso da FS, não sendo possível, portanto, assegurar sua qualidade, segurança e eficácia. 
Apresentaremos separadamente esses posicionamentos, bem como os argumentos por eles acionados durante o evento, tendo por base as notas taquigráficas da audiência e a presença de uma das autoras na ocasiáo.

\section{Defesa da ciência e da fosfoetanolamina sintética}

As falas dos convidados começaram com a apresentação do Dr. Gilberto Chierice, o principal cientista envolvido na confecção da substância, seguida de vários pesquisadores que foram seus orientandos ou parceiros nas décadas de pesquisa com a FS. De modo geral, eles apresentaram não só elementos que indicassem a efetividade da droga no tratamento do câncer como também passagens importantes da história da pesquisa sobre a substância, dando relevo ao fato de que esta resultava de investigação científica laboratorial e de que, se hoje não dispóe dos requisitos que as agências reguladoras exigem, isto não ocorreu por descuido ou esquiva mal-intencionada dos procedimentos.

Gilberto Chierice rebateu críticas centrais à FS, relativas à ausência de estudos científicos em seres humanos, justificando que esses testes começaram a ser realizados nas instalaçóes do Hospital Amaral Carvalho, localizado em Jaú. Na ocasião, não precisamente apontada, os testes clínicos visavam avaliar a eficácia da FS sobre cinco tipos de câncer. No entanto, com o encerramento do convênio com a USP por iniciativa do próprio hospital, as pesquisas não tiveram continuidade e os resultados parciais obtidos não foram divulgados pela equipe da unidade.

Esse hospital, na época, com esse convênio com a Universidade de São Paulo, foi transformado em hospital de pesquisa. As pesquisas foram iniciadas não pelas regras da Anvisa, mas pelas regras do Ministério da Saúde. Tem todas as autorizações. Quando dizem que não tem, tudo isso está feito, está documentado. [...] Cinco áreas: uro, gastro, cabeça e pescoço, mama e gineco. Cada uma dessas pessoas tem... O padrão eram onze pessoas para cada fase dessa. Essas fases foram feitas. Cadê? Vocês têm que pedir para o hospital. O hospital abandonou? Eu realmente não sei qual é o motivo, mas isso não me compete porque não é uma questão ética discutir isso aqui agora. $\mathrm{O}$ que nós temos que discutir é a ciência da história.

A defesa das condutas tomadas pela equipe de cientistas da FS seguiu na fala de Salvador Claro Neto, pesquisador da USP orientado por Gilberto Chierice e responsável pela síntese da substância. Ele se ocupou de explicar os motivos que levaram o IQSC a distribuir as cápsulas quando do encerramento das pesquisas clínicas no Hospital Amaral Carvalho. O cientista ressaltou o comprometimento ético implicado na distribuição das cápsulas, tendo em vista que não se poderia negar a FS a pessoas com câncer que vinham evidentemente se beneficiando de seu uso. 
Quer dizer, durante todo esse tempo, durante esses mais de vinte anos de distribuição, nós tivemos muitos casos de pessoas zeradas. Quer dizer, essa pesquisa realmente começou dentro do hospital. A partir do momento em que o hospital foi perdendo o interesse, começou a mandar os pacientes para a universidade, e o professor jamais iria deixar de dar uma cápsula para uma pessoa que estava em recuperação. Como uma pessoa em pleno processo de recuperação, de repente, não vai ter mais fosfoetanolamina?

Já Durvanei Augusto Maria, pesquisador que conduziu estudos com a FS no Instituto Butantã, desfez-se de acusaçôes de que a substância seria uma "garrafada", apontando que a FS náo havia resultado de "falsa ciência". O pesquisador argumentou que, ao contrário, a FS tinha em sua origem estudos rigorosos que demonstravam sua singularidade diante dos tratamentos convencionais no tocante a seu mecanismo de funcionamento e à ausência de efeitos colaterais.

Vim falar um pouco de ciência para mostrar que a fosfoetanolamina tem um princípio diferente de todos os quimioterápicos. [...] Vim mostrar para vocês que a fosfoetanolamina é um composto que age em células tumorais e não age em células normais. Este é o grande mecanismo seletivo de um composto que é efetivo e que não causa danos colaterais. [...] Vim mostrar que a fosfoetanolamina tem um princípio que tem que ser divulgado e que há uma ciência. Não é garrafada, não é curandeirismo, não é falsa ciência. [...] O alvo da fosfoetanolamina é a mitocôndria. A mitocôndria é uma estrutura, dentro da célula, que é capaz de deflagrar apoptose. É ela que controla os mecanismos de morte celular. Ela é sinalizada, na célula tumoral, para que morra, porque ela tem defeitos energéticos ou metabólicos.

Os trechos das exposiçóes do grupo de cientistas acima destacados mostram, portanto, uma série de argumentos que buscam caracterizar o percurso convencional da FS do ponto de vista do seu desenvolvimento científico. Se, por um lado, Chierice e Maria apontam que, em conformidade com o preconizado com as regulamentaçôes vigentes à época, pesquisas laboratoriais e clínicas haviam sido realizadas e apresentaram resultados positivos para os pacientes, por outro, Salvador explica que apenas a distribuição das cápsulas ocorreu fora das diretrizes sanitárias. A justificativa para tanto estava no comprometimento ético da equipe em fornecer tratamento eficaz para pessoas que dele necessitavam.

Os pacientes também compareceram à audiência e engrossaram o coro em defesa da FS. Sua presença era notável tanto nos relatórios contendo as mudanças de diagnóstico antes e depois do consumo da FS como em seus testemunhos. Estes, agora capazes de se distanciar dos seus leitos, convidavam a plateia a acompanhar seu relato pessoal e autorreferenciado de melhorias de saúde 
a partir do momento em que passaram a tomar as cápsulas com FS. Em relatos emocionados, instruíam os presentes na linguagem dos exames médicos, das alteraçôes das taxas, dos resultados positivos passíveis de serem não só medidos, mas sentidos e cuidadosamente avaliados e comunicados.

O testemunho de Bernadete Cioffi inaugurou as aclamadas falas dos pacientes. Portadora de câncer de mama agravado por uma metástase óssea, Bernadete relatou que, após o início do tratamento com a FS, pôde dispensar o uso de analgésicos - antes fundamentais para lidar com as dores lancinantes causadas pela doença. Sua fala fazia referência a exames e laudos como testemunhos de sua recuperação e trazia sua voz como seu principal ativo naquela audiência. Nos seus termos, o emprego da substância resultou na passagem de paciente "em cuidados paliativos" a alguém que podia comparecer a uma reunião em uma cidade diferente daquela onde mora, para testemunhar, com sua presença e seu discurso, em favor dos efeitos da "fosfo".

Os meus marcadores tumorais, pela primeira vez, baixaram. Também é fato que, desde o quarto dia de uso da "fosfo" eu náo faço mais uso de nenhum analgésico. E paciente com câncer sabe do que eu estou falando. (Palmas.) $\mathrm{O}$ analgésico nos tira a capacidade de ser humano. Ele nos tira a capacidade de pensar, ele nos tira a capacidade de reagir, ele nos tira até a capacidade, Pr. Marco Feliciano, de orar. O paciente dopado não consegue nem conversar com Deus. Hoje eu não faço uso de nenhum medicamento analgésico. E se for esse o benefício da fosfoetanolamina sintética, já valeu a pena (Palmas).

A fala acima, a exemplo da de outros pacientes que se pronunciaram, aponta para uma eficácia da FS cujo índice se encontrava na recuperação de faculdades antes perdidas, no "sentir-me melhor", no "voltar a viver". Antagonizando as referências ao risco potencial e à incerteza associada à substância presentes tanto em notícias quanto em posicionamentos de grupos contrários à sua utilização, as falas dos pacientes acionam uma certa dose de confissão: um falar da verdade intimista, experimentado no próprio corpo, recheado de anotaçóes sobre pequenas e grandes melhoras, sobre outras possibilidades de convívio com a doença, sobre um porvir que antes lhes era negado pelos efeitos deletérios das metástases ou dos quimioterápicos e analgésicos.

Ao comentar sobre a incapacidade de orar, imposta pelo uso de fortes analgésicos, Bernadete se dirigiu ao deputado federal Marco Feliciano (PSC/SP). Isso chama a nossa atenção para um conjunto de legisladores de extração conservadora que se vincularam formal e publicamente à causa da institucionalização da distribuiçáo da FS dessa audiência pública em diante. ${ }^{6}$ Tal movimento pode ser interpretado como uma tentativa de alguns 
parlamentares de catalisar o seu capital político a baixo custo. Ao se colocarem ao lado de quem, na audiência, apresentava-se como tiranizado pela burocracia do Estado, possivelmente este e outros políticos viram a possibilidade de amealhar simpatia em fileiras que ultrapassavam os seus usuais redutos.

\section{Defesa dos procedimentos-padrão}

Em contraste com o tom emocionado dos relatos e seu misto de indignaçáo com o que formulavam como uma violência de Estado, os órgãos de saúde pública, ciência e tecnologia se debruçaram sobre as etapas dos testes de medicamentos. Descrever tais etapas servia para apontar que, de um lado, não havia justificativas para aceitar quaisquer informaçóes obtidas fora de tais padróes como válidas para o uso da FS; e, de outro, bastava que a FS passasse por tais procedimentos para que se configurasse o seu o estatuto de medicamento (Castro, 2012).

O diretor-presidente da Anvisa, Jarbas Barbosa, apontou que as sucessivas fases de testes farmacêuticos consistiam num procedimento-padrão internacional cuja realização constituía um "ponto de passagem obrigatória” (Latour, 2001), para o qual não poderia haver exceçóes.

Eu não estou aqui nem para defender a fosfo nem para criticar. Estou aqui para apresentar qual é o processo - que não é só no Brasil, mas em qualquer lugar civilizado do mundo - utilizado para que a gente possa ter uma droga sendo utilizada em pessoas. [...] Qual é, então, a barreira que não pode deixar de ser realizada em nenhuma hipótese? A barreira para demonstrar, cabalmente, com metodologias científicas validadas no mundo inteiro, que esse medicamento ou essa nova droga, nova substância não é capaz de produzir males à saúde de quem vai ser objeto da pesquisa.

Insistindo na necessidade da realizaçáo de pesquisas segundo os padróes internacionais, Jailson Bittencourt, do Ministério de Ciência, Tecnologia e Inovação, declarou que o órgão já havia levantado informaçôes em alguns laboratórios públicos "sobre como acelerar esses testes clínicos de primeira e segunda fases". Nesse sentido, disse que, já que a realização de testes em seres humanos era necessária, o ministério se comprometia em colaborar tanto com a reduçáo dos tempos para realizaçáo dessas pesquisas quanto nas etapas para produção do FS em larga escala uma vez finalizadas as pesquisas e recebido o registro da Anvisa.

Por fim, mas ainda nesse mesmo caminho, o representante da Secretaria de Ciência, Tecnologia e Insumos Estratégicos do Ministério da Saúde, Adriano Massuda, apontou para a importância de orientar pacientes oncológicos a não abandonar os tratamentos convencionais. Estes sim, de uso instituído na prática 
médica e com bases científicas, deveriam continuar a ser utilizados e não poderiam ser deixados de lado em favorecimento da FS, cuja confiabilidade era duvidosa.

[...] Nós não podemos dar nenhum tipo de orientação com relação a deixar de fazer um tratamento que esteja instituído, a substituir algo que já esteja em andamento com uma pessoa que está em tratamento hoje no sistema de saúde, seja público, seja privado.

É notável, nas falas de representantes de instituiçôes do Estado, a impossibilidade de abrir exceção aos procedimentos-padrão, sob o risco de cometer um retrocesso científico, institucional e civilizatório. No entanto, diante das pressóes por tratamento para o câncer, parecia haver uma certa sensibilidade à questáo do tempo, indicada na disposição para "apressar" os procedimentos e, à medida que a FS fosse aprovada a cada etapa de pesquisa e avaliação sanitária, disponibilizá-la o mais rapidamente possível aos pacientes.

\section{Duas ausências, dois retrocessos: as divergências quanto aos riscos e às evidências}

Os tensionamentos entre os dois grupos seguiram durante toda a audiência pública, sendo particularmente perceptíveis a partir dos testemunhos. Após o diretor-presidente da Anvisa descrever a longa lista de requisitos para que a FS alçasse ao estatuto de medicamento, Amaro Vilson, paciente de câncer que abandonara a quimioterapia em favor do tratamento com a FS, mobilizou o seu corpo como lugar da reclamada "comprovação da eficácia da substância": "o remédio foi testado em mim! Tem cinco meses que eu tomo esse remédio! Foi testado em mim!"

Paciente de câncer hepático, Amaro não apenas testemunha pela institucionalização da distribuição da substância. Seu discurso de eficácia e segurança individual ${ }^{7}$ coloca em jogo a própria lógica dos órgãos reguladores e, sobretudo, os próprios procedimentos de chancela para novos medicamentos. Ao enunciar seu corpo, sua experiência com a FS e sua saúde melhorada como marcos da existência de "testes" que possibilitam afirmar o efeito da substância tanto na melhoria do seu estado de saúde quanto na inexistência de efeitos adversos, Amaro aponta para o quanto as exigências regulatórias de produção e avaliação de evidências farmacêuticas lhe parecem consistentes com sua própria experiência. Seu discurso, nesse sentido, contém uma dimensão de desafio, na medida em que instaura uma questão sobre a legitimidade das agências reguladoras e seus parâmetros de avaliação. 
Sua fala, afirmativa da experiência individual como legítima produtora de conhecimento confiável, desafia o rito ordinário da regulamentação de medicamentos e se irmana parcialmente à afirmação do médico Renato Meneguelo, que durante a sessão observou, ao apresentar fotografias e vídeos de pacientes que tiveram melhoras sensíveis após o uso da FS, que

contra fatos não há argumentos. Ponto. (Palmas.) Esta é a única coisa que se tem de falar. 'Quero mais papel, mais papel e mais papel.' Tome papel. Quero vida, sobrevida, com dignidade. Desculpem-me o desabafo, mas eu já não aguento mais fazer óbito de amigo, vocês me desculpem. Obrigado. (Palmas.) Senhores, por favor, eu imploro para vocês, ajudem-nos. Nós queremos somente o que a sociedade científica quer: teste clínico. Estamos pedindo testes clínicos. Quantos testes clínicos sáo feitos no Brasil, de fase 1, 2 e 3? Eu estou pedindo teste clínico. Não estou pedindo nada demais. Não estou pedindo dinheiro. Nós nunca pedimos dinheiro. Estou pedindo teste clínico. Por favor! Por favor! Ajoelho de frente para vocês e peço: por favor!

O depoimento acima foi feito parcialmente em prantos e de joelhos diante dos presentes à audiência pública. Nele, Renato Meneguelo, médico que defendera uma dissertação de mestrado sob a orientação de Gilberto Chierice e que, por seus relatos, administrou a substância a pacientes com sucesso, argumenta que as autoridades sanitárias demandam muito "papel", mesmo diante dos sinais cabais de melhora nos pacientes. Por outro lado, o médico alinha-se à comunidade científica em geral e pede o acatamento dos testemunhos e relatórios de caso pelas agências como fatos suficientes para acelerar os testes com a substância - mas não para deles prescindir.

Neste ponto, sugerimos que na audiência pública, as "ausências" eram centrais. Por um lado, os já referidos órgãos demoravam-se em anotar a ausência de testes em seres humanos, o que configuraria um cenário, em seu entendimento, pleno de riscos para os pacientes, visto não haver evidências científicas dos efeitos antineoplásico e não nocivo da FS. Por outro, os pacientes e o coletivo mobilizado em torno da institucionalização da distribuiçáo da substância descreviam a ausência de cápsulas para o tratamento como o maior dos riscos - ou de morrerem, ou de terem de retornar aos tratamentos oncológicos convencionais e seus efeitos colaterais.

O risco é mobilizado duas vezes, mas de maneiras distintas. Na primeira vez, quando acionado pelos representantes de órgáos do Estado, o risco está relacionado à possibilidade de expor pacientes oncológicos a uma terapêutica náo regulada pela autoridade de vigilância sanitária. A reivindicação do dever discricionário de mediar quaisquer interaçóes com substâncias farmacêuticas traz 
à baila a noção de risco sanitário, descrita por Souza e Costa (2010:3337) como "a probabilidade de ocorrência de um evento, agravo ou dano, em uma determinada população exposta a um determinado fator de risco". As autoridades de saúde presentes na audiência parecem assim sugerir que, ao distribuir uma substância sem atender aos experimentos padronizados e ao rito regulatório padrão, os pacientes seriam lançados no perigo do desconhecido e desregulamentado. Com isso, imperaria o recurso ao "curandeirismo" e ao "charlatanismo", escancarados pelos anúncios de fórmulas "milagrosas" de cura do câncer.

$\mathrm{Na}$ segunda vez, cientistas e pacientes que se mobilizam em torno da FS caracterizam o risco como um fator ensejado pelo próprio Estado. Este, ao desmobilizar o laboratório que se envolvia na produção da substância e a distribuía gratuitamente à população, ameaçaria deixar os convalescentes sem cápsulas. A substituição do tratamento convencional pelas cápsulas de FS feita por Amaro Vilson e a fala de Bernadete Cioffi sobre sua experiência com analgésicos sugerem, ainda, que a não liberação das cápsulas levaria os doentes de volta aos cuidados paliativos ou ao recurso aos quimioterápicos aprovados pela Anvisa. ${ }^{8}$

Apesar das diversas manifestaçóes contrárias à pertinência dos procedimentos de produção de evidência e de registro sanitário demandados pelas autoridades, os defensores da FS não os recusam completamente. Ao contrário, há um movimento duplo no qual a crítica aos procedimentos-padrão, frequentemente mencionados sob a rubrica negativa de "burocracia" ou "papel", impulsiona a demanda pelo reconhecimento dos testemunhos como peças de demonstração do funcionamento da FS em organismos humanos e a afirmaçáo da identidade dos pesquisadores da substância como cientistas sérios e éticos.

Nesse enquadramento, encontramos um conjunto de aproximaçóes dos eventos da FS com o caso estudado por Aditya Bharadwaj $(2013,2014)$ acerca dos tratamentos com células-tronco oferecidos por uma clínica indiana que, mesmo não estando avalizados pela comunidade científica, são reconhecidos como seguros, eficazes e legítimos tanto por seus usuários quanto pela médica responsável por sua criação e aplicação clínica. Segundo o autor, as terapias celulares utilizadas na clínica são severamente criticadas pela comunidade científica e jornalística de um modo geral, iluminando situaçóes por ele agrupadas sob o conceito de ética da consensibilidade.

Por um lado, tal ideia aponta para a percepção de que o "ético na produção de um terreno consensuável de práxis e pensamento é fundamentalmente institucional, um corpo codificado de conhecimento abstrato circunscrito por um conjunto de regras e regulamentaçôes" (Bharadwaj, 2013:28). E, por outro, identifica um esquema político classificatório e hierarquizante no qual 
"a ausência [de] um contexto disciplinar é vista como promotora de práticas inseguras, antiéticas e inviáveis que podem ser ineficazes, arriscadas e perigosas” (Bharadwaj, 2014:85).

Contrastivamente, Bharadwaj conceitua as práticas de experimentação e tratamento realizadas em seu contexto de pesquisa a partir da ideia de eticalidade subalterna: "uma instância irônica, crítica opositora de demandas por consensibilidade (bio)científica e (bio)ética ao mesmo tempo em que busca se tornar normalizada e incorporada e interior de suas dobras" (2013:26). Assim, produçóes científicas de contextos sociopolíticos subalternos habitam um lugar ambíguo, onde, ao mesmo tempo em que provocam os limites do corpo normativo e ético hegemônico que rege o campo científico global, buscam ser incorporados a ele a partir de suas margens.

De modo semelhante, nota-se no caso da FS que uma crítica, somada ao desejo pela fusão com os meios usuais de validação, se faz por meio do emprego do testemunho: uma narrativa ancorada na experiência que se vale do próprio corpo para sinalizar a eficácia de uma forma terapêutica. ${ }^{9}$ Esse instrumento, tomado como índice da efetividade da FS por seus defensores, figura como justificativa para a continuidade da distribuição das cápsulas, a despeito da inexistência das autorizaçóes sanitárias. Ao mesmo tempo, os testemunhos catapultam o argumento pela aceleração dos testes e autorizaçóes institucionais ordinárias, dada a necessidade de continuidade dos tratamentos.

O papel do testemunho, entretanto, extrapola os limites da tensão entre a eticalidade e a consensibilidade. Bharadwaj (2013) observa de maneira muito precisa que os testemunhos são aquilo que resta quando (ainda?) não se dispóe dos meios de validação de uma tecnologia terapêutica. Concomitantemente, seu compartilhamento abre caminhos para o reconhecimento da experiência de cada sujeito no nível somático:

enquanto a clínica continua a reter artigos científicos, o testemunho e a experiência de recuperaçấo dos pacientes começam a ter um efeito suplementar. Esta medida contingente, tampão, apesar de ser uma resposta inadequada às necessidades estruturais e éticas implicadas na ética da consensibilidade, dá acesso ao mundo dos pacientes e a suas lutas somáticas (Bharadwaj, 2013:34).

No debate que acompanhamos, entretanto, é justamente o fato de remeter a esse universo somático e confessional o que, por um lado, compromete a credibilidade dos testemunhos diante das autoridades do Estado e, por outro, habilita os pacientes a depor em favor da FS. João Camillo Penna (2013), a propósito da obra de Agamben, observa que a testemunha é alguém que não 
precisa necessariamente possuir um caráter excepcional. Ao contrário, de acordo com o autor, é o próprio caráter ordinário da testemunha e do conteúdo de seu testemunho o que os qualifica enquanto tais.

A testemunha é por definição uma pessoa ordinária, que testemunha enquanto pessoa ordinária, sobre o ser ordinário da vida, que é nada mais que ordinária. É o caráter qualquer da vida, para utilizar uma categoria que Agamben estudara anteriormente, que é essencialmente vida de qualquer um, o objeto de interrogação do testemunho (Penna, 2013:55).

Os pacientes chamados à audiência náo importaram pela excepcionalidade de seu relato. Para os defensores da eficácia da FS, o testemunho valeu na medida em que pôde ser apresentado por qualquer um que estivesse em tratamento com a droga. Decerto que a testemunha pode se converter em um rosto, no momento em que seu relato é alçado à condição de "relato representativo", mas nas controvérsias públicas envolvendo a eficácia da substância a testemunha pareceu, necessariamente, um sujeito "ordinário" (Penna, 2013). No recurso às falas de usuários da FS durante a audiência, é exatamente o caráter ordinário de seu testemunho que pretende tornar o seu relato confiável, uma vez que, enquanto parte que representa a si mesma, o sujeito do testemunho também pretende ser a "evidência" da eficácia da droga.

Para os representantes do Estado, entretanto, os testemunhos advindos dos próprios usuários operaram como evidência da fragilidade da afirmação do potencial terapêutico da FS. Se seguirmos a elaboração de Donna Haraway (1989) a respeito das práticas consensuais de produção de fatos científicos, temos uma interessante pista para refletir sobre o contraste eloquente entre as percepções sobre os testemunhos na audiência pública sobre a FS. A autora aponta que, apesar de estarmos diante de testemunhos quando tratamos do universo da ciência, essas são experiências mediadas por uma série de elementos técnicos, sociais e interpretativos que lhes distinguem da experiência ordinária.

Os fatos em si mesmos são tipos de histórias, de testemunho da experiência. Mas a provocação de uma experiência requer uma tecnologia elaborada - incluindo ferramentas físicas, uma tradição acessível de interpretação, e relações sociais específicas. Não é qualquer coisa que pode emergir como fato; não é qualquer coisa que pode ser vista, feita e assim contada (Haraway, 1989:4).

Nesse cenário, observa-se, portanto, que para as narrativas dos testemunhos emergirem como "fatos científicos" ou "provas" da eficácia e segurança da FS, estes devem ser constituídos exclusivamente nos marcos e procedimentos consensuais da experimentação contemporânea. Nesse sentido, foram desqualificadas as 
experiências individuais e íntimas dos pacientes, em privilégio da construção das condiçóes para a realização de pesquisas clínicas com a FS. Estas, obedecendo às diretrizes metodológicas, teóricas, éticas e regulatórias para o desenvolvimento de medicamentos, ofereceriam as evidências necessárias ao referendo ou descarte de seu uso terapêutico. No embate com as autoridades estatais, os testemunhos foram desqualificados em nome da produção de evidências científicas por meio de pesquisas em seres humanos segundo procedimentos padronizados internacionalmente.

\section{Comentários finais}

Neste artigo, procuramos oferecer uma descrição de parte do debate relativo à liberação da FS no Brasil, com foco sobre a controvérsia que teve lugar na audiência ocorrida no Senado Federal em outubro de 2015. Desde entáo, ocorreram outros eventos relativos à liberação da substância. Em 13 de março de 2016, depois de aprovaçáo no Senado Federal, a presidenta Dilma Rousseff sancionou a Lei 13.269, que autorizava o uso da FS em pacientes portadores de câncer. Contudo, em 19 de maio do mesmo ano, o STF suspendeu a eficácia da referida legislação, acolhendo o argumento apresentado na Ação Direta de Inconstitucionalidade 5.501, impetrada pela Associação Médica Brasileira, relativo ao desconhecimento sobre os riscos e a eficácia da FS devido à ausência de estudos científicos válidos.

A decisão do STF interrompeu completamente a distribuição da FS pelo IQSC. A produção das cápsulas de FS passou então à incumbência de empresas farmacêuticas nacionais, com a finalidade de subsidiar pesquisas clínicas no estado de São Paulo. Tais laboratórios se tornaram, a partir de então, alvos dos investimentos de judicializaçáo dos pacientes, que conseguiram acesso à FS por meio de mandados de busca e apreensão expedidos pela Justiça do estado, que obrigam os laboratórios a lhes entregar a substância (Cambricoli, 2016). Mais recentemente, no início de 2017, o portal G1 publicou uma notícia relativa ao decreto de suspensão da inclusão de novos pacientes nos testes com a FS por parte do Instituto do Câncer do Estado de São Paulo, "devido à ausência de 'benefício clínico significativo’ nas pesquisas realizadas até o momento” (Dantas, 2017).

Ao fazermos um balanço desse caso, notamos que as agências do Estado parecem se orientar por um conjunto de princípios que Nikolas Rose nomeou de biomoralidade: "aquelas práticas e modos de pensar [...] cujo objetivo é desenvolver princípios e promulgar códigos e regras sobre como a pesquisa ou o trabalho clínico na biomedicina deve ser conduzido" (2008b:47). Segundo Rose, tais princípios são fundamentais para "disciplinar estas dificuldades" (2008b:47) contemporâneas concernentes à centralidade do "bio" na vida cotidiana, mediante a proposição 
de respostas padronizadas a questôes como: "os procedimentos adequados foram seguidos? As permissōes adequadas foram obtidas? A confidencialidade foi garantida? O consentimento informado foi obtido?” (2008b:47).

Diante da noçáo de biomoralidade, entendemos que a centralidade do testemunho dos pacientes residiu em sua tentativa de oferecer aos gestores públicos que decidiam sobre a regulamentaçáo da FS mais do que uma moralidade alternativa. Tal como no exemplo dos grupos de pacientes envolvidos na pesquisa sobre medicamentos para o tratamento do HIV, descritos por Collins e Pinch (2002), que agiram ativamente em busca de alternativas para o tratamento da enfermidade no período que precedeu o desenvolvimento dos coquetéis, os testemunhos sobre a eficácia da FS ora descritos podem ser compreendidos como algo mais do que instrumentos de pressão. Eles têm o potencial de propor às agências reguladoras uma reorientação dos meios de verificação da eficácia e segurança de medicamentos e quiçá de alterá-las. Essa possibilidade, entretanto, diante da complexidade do cenário de biomoralidade e ética da consensibilidade, parece estar sendo sistematicamente descartada.

A despeito disso, compreendemos que, por meio da apresentação dos seus testemunhos na audiência, os pacientes estiveram, a um só tempo, disputando e partilhando a autoridade em relação a quem pode declarar um medicamento como medicamento - e, nesse passo, assumindo também responsabilidades sobre a identificação, mensuração e mitigação dos riscos da sua utilização. E o fizeram não na defesa de uma substância cujo contexto de produção seja estrangeiro às ciências, mas de um produto que nasceu em laboratórios. Os testemunhos são, nesse sentido, tanto o que resulta da controvérsia da fosfoetalonamina quanto o que pretende tornar a continuidade da positividade dos seus efeitos não um fato indisputável, mas um produto com eficácia relativa, relacionada a seu contexto de produçáo e àqueles corpos cujo caráter ordinário da experiência desafia os rigores e a generalidade dos procedimentos institucionais.

Recebido em: 29/12/2016

Aprovado em: 23/5/2017 
Rosana Castro é doutoranda do Programa de Pós-Graduação em Antropologia Social da Universidade de Brasília. Tem experiência em pesquisas e publicaçóes nos temas de açóes coletivas para acesso a medicaçôes experimentais, vigilância sanitária de medicamentos, avaliação de tecnologias em saúde e direitos reprodutivos. Atualmente, investiga o campo da pesquisa experimental farmacêutica em seres humanos no Brasil. Contato: rosacastro27@gmail.com

Rafael Antunes Almeida é doutor em antropologia pelo Programa de PósGraduaçáo em Antropologia Social da Universidade de Brasília e professor de antropologia na Universidade da Integração Internacional da Lusofonia AfroBrasileira. Tem experiência em sociologia e antropologia da ciência e da tecnologia. Suas áreas de investigação principais são o estudo de controvérsias científicas e de coletivos de paracientistas. Contato: almeida.rafaelantunes@gmail.com

\section{Notas}

1. Uma versão deste trabalho foi apresentada na $30^{\text {a }}$ Reunião de Brasileira de Antropologia, realizada entre 3 e 6 de agosto de 2016 em João Pessoa (PB). Agradecemos às coordenadoras do GT 59 - Risco: entre Teoria e Práticas Sociais/Coletivas, Ednalva Maciel Neves e Leila Sollberger Jeolás, bem como aos participantes do grupo, pelos valiosos comentários e sugestóes ao trabalho. Agradecemos igualmente ao grupo de pesquisa coordenado pela professora Soraya Fleischer, cujos comentários possibilitaram enriquecer e aperfeiçoar este artigo.

2. A literatura relativa ao tema das controvérsias científicas é vasta e talvez seja apropriado dizer que o tema está imbricado no próprio florescimento dos estudos sociais da ciência e da tecnologia. Partindo das primeiras formulaçôes da Escola de Bath, que teve como principal representante Harry Collins (1981), pode-se dizer que os primeiros estudos se voltaram às controvérsias porque nelas entrevia-se o tema da "flexibilidade interpretativa" (Collins, 1981:5) na ciência. Ademais, os processos de fechamento de controvérsias eram ocasiôes apropriadas para compreender a natureza sociopolítica do empreendimento científico. Em certo sentido, o estudo das controvérsias se acomodaria bem ao propósito regente do campo CTS (Ciência, Tecnologia e Sociedade) nas décadas de 1970 e 1980, que se voltaram para o estudo da ciência em construção. "Ciência em ação" (Latour, 1987) deve ser entendida como o coroamento deste projeto. Depois, a obra de Latour deu um lugar amplificado ao estudo das controvérsias, ao fazê-las o objeto mesmo da antropologia simétrica. "Reassembling the social" (Latour, 2005) está construído sobre o pressuposto do estudo de coletivos em formação (group formations), mas aí o estudo das controvérsias converteu-se em método, isto é, no instrumento privilegiado de pesquisa da ANT. 
3. Ao lado do pleito coletivo direcionado à Anvisa pela realocação do óleo rico em canabidiol na lista de substâncias controladas e liberadas para uso terapêutico, analisado por Oliveira (2016), o caso da FS mostra o quanto a Anvisa vem se tornando um alvo de ações biossociais por tratamentos experimentais. Em 2014, a agência formalizou os procedimentos para solicitaçáo individual ou coletiva de medicaçóes em fase de pesquisa ou recém-pesquisadas, mas ainda sem registro no país (Anvisa, 2013). Em um levantamento realizado pela revista Época, relata-se que as solicitaçóes de acesso individual a medicações experimentais à Anvisa aumentaram 53\% entre 2015 e 2016 (Buscato, 2016).

4.Disponívelem:https:/www.facebook.com/Fosfoetanolamina-872310352806286/. Acesso em: 7/6/2016.

5. À época dessa audiência, o senador Cristovam Buarque estava filiado ao PDT. Atualmente, é filiado ao PPS.

6. Deputados federais como Marco Feliciano (PSC/SP), Wellinton Prado (PMB/MG) e Leandre Dal Ponte (PV/PR), bem como os senadores Ivo Cassol (PP-RO), Blairo Maggi (PP/MT) e Waldemir Moka (PMDB/MS), são exemplos de parlamentares que se mobilizaram em torno na FS por meio da proposição de requerimentos para audiências públicas e de projetos de lei para sua regularização.

7. Caso semelhante de tensionamento entre a avaliação individual de eficácia e segurança realizada por médicos na prática clínica e a pesquisa clínica, que toma tais aspectos dos medicamentos com ênfase populacional, foi observado por Castro (2014), no caso da controvérsia em torno da regulamentaçâo dos emagrecedores no Brasil.

8. A estabilização das percepções de "risco" dos agentes do Estado e a desqualificação dos testemunhos tem aqui um caráter provisório, dado que nosso recorte não permite afirmar peremptoriamente o desfecho da controvérsia, que ainda se encontra em aberto.

9. Embora os cientistas defensores da fosfoetalonamina sintética tenham sido chamados a falar na audiência pública, seu relato só pode testemunhar pela eficácia da droga apelando às referências aos testemunhos dos pacientes. Por certo, ambos se valem do recurso à narrativa dos convalescentes, mas os primeiros o fazem a partir de uma leitura de segunda mão.

\section{Referências}

ALMEIDA, Antunes Rafael. 2015. Objetos intangiveis: ufologia, ciência e segredo. Tese de Doutorado, Universidade de Brasília.

BHARADWAJ, Adytia. 2013. "Ethic of consensibility, subaltern ethicality: the clinical application of embryonic stem cells in India”. BioSocieties, 8(1):25-40.

. 2014. "Experimental subjetification. the pursuit of human embryonic stem cells in India”. Ethnos, 79(1):84-107. 
BIEHL, João \& PETRYNA, Adriana. 2016. "Tratamentos jurídicos: os mercados terapêuticos e a judicialização do direito à saúde". História, Ciências, Saúde-Manguinhos, 23(1):173-192.

BRASIL. 1976. Presidência da República. Casa Civil. Lei 6.360, de 23 de setembro de 1976. Disponível em: http://www.planalto.gov.br/ccivil_03/leis/L6360.htm. Acesso em: $8 / 5 / 2016$.

. 2013. Agência Nacional de Vigilância Sanitária. Resolução de Diretoria Colegiada 38, de 12 de agosto de 2013. Disponível em: http://portal.anvisa.gov.br/ documents/33880/2568070/rdc0038_12_08_2013.pdf/9c3a940e-c62e-4ead-99c02f986d5880a2. Acesso em: 8/5/2016.

- 2015a. Agência Nacional de Vigilância Sanitária. Resolução de Diretoria Colegiada 9, de 20 de fevereiro de 2015. Disponível em: http://bvsms.saude.gov.br/bvs/ saudelegis/anvisa/2015/rdc0009_20_02_2015.pdf. Acesso em: 8/5/2016.

- 2015b. Supremo Tribunal Federal. Medida Cautelar. Disponível em: http://www.stf.jus.br/portal/jurisprudencia/listarJurisprudencia.asp? s1 $=\% 28 \% 28$ fosfoeta nolam ina\%29\%29+NAO+S\%2EPRES\%2E \&pagina $=2$ \&base=baseMonocraticas \&url=/portal/jurisprudencia/listarJurisprudencia.asp. Acesso em: $1 / 6 / 2016$.

BUSCATO, Marcela. 2016. "Pacientes com câncer conseguem de graça remédios que não existem no país". Época, 17 de julho de 2016. Disponível em: http://epoca.globo.com/vida/noticia/2016/07/pacientes-com-cancerconseguem-de-graca-medicamentos-que-nao-existem-no-pais.html. Acesso em: $27 / 11 / 2016$.

CAMBRICOLI, Fabiana. 2016. Teste da 'pílula do câncer' deve ser adiado pela terceira vez. Estado de S. Paulo, $1^{\circ}$ de julho de 2016. Disponível em: http://saude.estadao.com. $\mathrm{br} /$ noticias/geral,teste-da-pilula-do-cancer-deve-ser-adiado-pela-3-vez, 10000060246. Acesso em: 27/11/2016.

CASTRO, Rosana. 2012. No fiel da balança: uma etnografia da regulamentação sanitária de medicamentos para emagrecer. Dissertação de Mestrado, Universidade de Brasília.

- 2014. "Regulamentação sanitária de medicamentos: a controvérsia dos emagrecedores”. In: Jaqueline Ferreira \& Soraya Fleischer (ed.). Etnografias em serviços de saúde. Rio de Janeiro: Garamond. pp. 299-322.

CESARINO, Letícia. 2006. Ascendendo as luzes da ciência para iluminar o caminho do progresso: ensaio de antropologia simétrica da lei de biossegurança brasileira. Dissertação de Mestrado, Universidade de Brasília. 
CHIEFFI, Ana Luiza \& BARATA, Rita Barradas. 2009. "Judicialização da política pública de assistência farmacêutica e equidade". Cadernos de Saúde Pública, 25(8):1839-1849.

COLLINS, Harry. 1981. Stages in the empirical programme of relativism. Social Studies of Science, 11:3-10.

COLLINS, Harry \& PINCH, Trevor. 2002. The golem at large: what you should know about technology. New York: Cambridge University Press.

DANTAS, Carolina. 2017. Fosfoetalonamina: Instituto de Câncer suspende novos testes devido a "ausência de benefício clínico significativo". Portal G1, 31 de março de 2017. Disponível em: http://g1.globo.com/bemestar/noticia/fosfoetanolamina-institutodo-cancer-suspende-testes-devido-a-ausencia-de-beneficio-clinico-significativo.ghtml. Acesso em: 4/7/2017.

HARAWAY, Donna. 1989. Primate visions: gender, race and nature in the world of modern science. New York: Routledge.

LATOUR, Bruno. 1987. Science in action: how to follow scientists and engineers through society. Cambridge: Harvard University Press.

2001. A esperança de Pandora: ensaios sobre a realidade dos estudos cientificos.

Bauru: Edusc.

2005. Reassembling the social: an introduction to actor-network-theory. Oxford: Oxford University Press.

LEDFORD, Heidi. 2015. "Brazilian courts tussle over unproven cancer treatment". Nature: International Weekly Journal of Science, 527(7579). Disponível em: http://www. nature.com/news/brazilian-courts-tussle-over-unproven-cancer-treatment-1.18864. Acesso em: 1/6/2016.

MACHADO, Marina Amaral et al. 2011. "Judicialização do acesso a medicamentos no Estado de Minas Gerais, Brasil”. Revista de Saúde Pública, 45(3):590-598.

MARQUES, Silvia Badim. 2008. "Judicialização do direito à saúde”. Revista de Direito Sanitário, 9(2):65-72.

OLIVEIRA, Fabiana. 2016. Maconheirinhos: cuidado, solidariedade e ativismo de pacientes e seus familiares em torno do óleo de maconha rico em canabidiol (CBD). Dissertação de Mestrado, Universidade de Brasília.

PENNA, João Camillo. 2013. Escritos da sobrevivência. Rio de Janeiro: 7 Letras. 
PIOVEZAN, Stephanie. 2015. "Pacientes pedem na justiça que USP forneça cápsulas no combate ao câncer”. Portal G1, 17 de agosto de 2015. Disponível em: http://g1.globo. $\mathrm{com} / \mathrm{sp} / \mathrm{sao}$-carlos-regiao/noticia/2015/08/pacientes-pedem-na-justica-que-usp-fornecacapsula-de-combate-ao-cancer.html. Acesso em: 1/6/ 2016.

NELKIN, Dorothy \& HILGARTNER, Stephen. 1986. "Disputed dimensions of risk: a public school controversy over AIDS”. The Milbank Quarterly, 64:118-142.

RABINOW, Paul. 1999. "Artificialidade eiluminismo: dasociobiologia à biossocialidade”. In: _______. Antropologia da razão: ensaios de Paul Rabinow. Rio de Janeiro: Relume Dumará. pp.135-158.

ROSE, Nikolas. 2008a. The politics of life itself: biomedicine, power, and subjectivity in the twenty-first century. Princeton and Oxford: Princeton University Press.

. 2008b. "The value of life: somatic ethics $\&$ the spirit of biocapital". Daedalus, 137(1):36-48.

SOUZA, Gisélia S. \& COSTA, Ediná A. 2010. "Consideraçōes teóricas e conceituais acerca do trabalho em vigilância sanitária, campo específico do trabalho em saúde”. Ciência \& Saúde Coletiva, 15(3):3329-3340.

TOLEDO, Marcelo. 2015. "Processos sobre 'cápsula do câncer' congestionam Justiça em São Carlos”. Folha de S. Paulo, 28 de outubro de 2015. Disponível em: http://wwwl. folha.uol.com.br/equilibrioesaude/2015/10/1699549-processos-sobre-capsula-docancer-congestionam-justica-em-sao-carlos.shtml. Acesso em: 20/6/2016.

TOMAZELA, José Maria. 2015. "TJ suspende distribuição de suposto remédio contra câncer”. Estado de S. Paulo, 29 de setembro de 2015. Disponível em: http://saude. estadao.com.br/noticias/geral,tj-suspende-distribuicao-de-suposto-remedio-contracancer,1771233. Acesso em: 1/6/2016.

UNIVERSIDADE DE SÃO PAULO. 2015. USP divulga comunicado sobre a substância fosfoetalonamina. Disponível em: http://www5.usp.br/99485/usp-divulgacomunicado-sobre-a-substancia-fosfoetanolamina. Acesso em: 1/6/2016.

UNIVERSIDADE DE SÃO PAULO. Instituto de Química de São Carlos. 2014. Portaria IQSC 1389. Disponível em: http://www5.iqsc.usp.br/files/2015/09/Portariadistribuicao-de-medicamentos.pdf. Acesso em: 27/11/2016.

VIEIRA, Fabiola Sulpino \& ZUCCHI, Paola. 2007. "Distorções causadas pelas ações judiciais à política de medicamentos no Brasil”. Revista de Saúde Pública, 41(2):214-222. 


\section{Resumo}

Em 2015, a substância fosfoetanolamina sintética se tornou alvo de intensas disputas judiciais, científicas e institucionais. Cápsulas eram fabricadas e distribuídas pelo Instituto de Química do campus de São Carlos da Universidade de São Paulo a pacientes com câncer, sem o aval da reitoria da universidade ou das autoridades sanitárias, as quais argumentavam que a substância não tinha passado por todas as etapas de pesquisa. $\mathrm{O}$ caso ganhou a atenção da mídia, sobretudo diante de depoimentos de pacientes que utilizaram a substância e afirmavam que nela havia a cura para o câncer. A tais pacientes, juntou-se o grupo de cientistas responsáveis pela pesquisa, produção e distribuição das cápsulas, que defendia sua efetividade com resultados de estudos em animais e testemunhos de pacientes curados de modalidades agressivas da doença ou em fase de tratamento. Diante da controvérsia, este trabalho apresenta uma etnografia de debates públicos, documentos e produção jornalística sobre a substância e reflete a respeito de como esse caso interpelou distintas articulaçôes da categoria de "risco", bem como provocou os limites da legitimidade das práticas dominantes de produção de evidência científica e de regulamentação sanitária de medicamentos.

Palavras-chave: Evidências científicas, testemunho, risco, medicamentos, controvérsias científicas.
In 2015 a substance called synthetic phosphoethanolamine was under intense judicial, scientific, and institutional dispute in Brazil. The drug was manufactured and distributed by the Institute of Chemistry of the São Carlos campus of the University of Sáo Paulo to patients with cancer without the approval of the university's dean or the state's health authorities, who argued that the substance had not gone through all the stages of a clinical trial. The case gained attention of the media, especially because of testimonies of patients who had used phosphoethanolamine and believed that it could cure cancer. The group of scientists responsible for the research, production and distribution of the drug advocated its effectiveness relying on results from animal studies and on testimonies of patients that were cured of aggressive cancer or were being treated with it. This paper presents an ethnographic description of public debates, documents and media news on the substance and reflects on how this case addressed different articulations of the category of "risk", as well as challenged the limits on the legitimacy of dominant practices of production of scientific evidence and state regulation of pharmaceuticals.

Key-words: Scientific evidence, testimony, risk, pharmaceuticals, scientific controversy. 